\title{
Death of neurasthenia and its psychological
}

\section{reincarnation}

\section{A study of neurasthenia at the National Hospital for the Relief and Cure of the Paralysed and Epileptic, Queen Square,}

London, 1870-1932

\section{RUTH E. TAYLOR}

\begin{abstract}
Background The diagnosis of neurasthenia appeared in 1869 and rapidly became fashionable and highly prevalent. It disappeared almost completely, producing ongoing debates about what happened to the disease, which have not so far been informed by empirical data.
\end{abstract}

\begin{abstract}
Aims To use empirical historical hospital data from one specific hospital to explore several controversies about neurasthenia, including what happened to the disorder.
\end{abstract}

\begin{abstract}
Method The annual reports of Queen Square Hospital were examined from 1870 to 1947. The prevalence of neurasthenia diagnoses as a proportion of total discharges was recorded. The possible diagnostic categories into which neurasthenia could have been reclassified were identified. Textbooks and writing by neurologists working at the hospital during this period were examined.
\end{abstract}

Results Neurasthenia accounted for 6-11\% of total discharges from the late 1890s to 1930, when it virtually disappeared. Men accounted for 33-50\% of cases.

\section{Conclusions Neurasthenia affected both the upper and working classes and both men and women. Neurologists, not psychiatrists, continued to see the disorder well into the 20th century. Neurasthenia did not disappear, but was reclassified into psychological diagnoses.}

Declaration of interest R.E.T. was funded by a Wellcome Clinical Epidemiology Fellowship.
The term neurasthenia was introduced by George Beard in 1869 (Beard, 1869). Although it was recognised from its inception that neurasthenia was associated with a heterogeneous symptom cluster, the core features were held to be excessive physical and mental fatigue and muscle weakness. Common mental symptoms were insomnia, lack of concentration, depression, fears and irritability (Gosling, 1987). It spread rapidly and by the turn of the century was being described as "the fashionable disease" (Chricton Miller, 1920). This fashionable aspect to the diagnosis can cloud our attempts to get a clear picture of the disorder and its apparent disappearance. There always were many different views of neurasthenia (Shorter, 1992). However, there are several very prevalent myths about it, some of which existed during its heyday, and others of which have been perpetuated since. The aim of the current study is to examine the reality of these myths in the light of empirical data collected from historical records at the National Hospital, Queen Square, London. Specifically, the following hypotheses are tested on the Queen Square data: (1) neurasthenia was not a diagnosis prevalent in the poor; (2) it was a disease of women; (3) the disorder largely disappeared after its 19th century heyday; (4) neurologists stopped seeing neurasthenia, which became the province of psychiatry.

\section{Myths outlined \\ Social-class bias}

Beard propagated his view that the illness was due to a deficiency in nervous energy, often found in businessmen or others exposed to the competition, luxuries and vices of modern society (Beard, 1972). He also felt it was more common among those with a more refined nervous system, including intellectuals and professionals. Indeed, he himself had suffered from the disorder, as had other physicians such as Dowse and
Mitchell, who were closely connected with the condition (Jewell, 1881; Blocq, 1894). Wessely (1996), in his history of neurasthenia, writes that although initially a fashionable disease of the upper classes, it spread downward through the social classes. $\mathrm{He}$ quotes a series of papers from 1903 to 1911 which show that it was common in Jewish immigrants, the garment workers of New York and the working-class patients of the Vanderbilt clinic in New York. There is an implication here that the disease spread to the lower classes. However, it may always have been prevalent across all social groups, but was not observed in the lower classes by the leading lights of neurasthenia such as Beard and Mitchell, whose patients were exclusively drawn from higher social groups.

\section{Neurasthenia was a female malady}

The work of Elaine Showalter presents a feminist thesis on neurasthenia. She paints a picture of neurasthenia in which its female victims languished fatigued, often incapable of walking, on the chaise-longues of London and New York, and included such well-known literary figures as Virginia Woolf, Charlotte Perkins Gilman and Alice James. Although she does mention the occurrence of the illness in middle-class men the main thrust of her argument is that it arose in women as a form of protest against their empty and unfulfilled lives (Showalter, 1985). Primary sources reveal contradictory views on the gender distribution of neurasthenia. Some writers obviously saw it as a disease of professional and intellectual men, for example, "it is a disease of bright intellects, its victims are leaders and masters of men, each one a captain of industry" (Pritchard, 1905). Dowse comments that in his experience it is common among clergymen prone to overwork (Dowse, 1892). However, there was also a view that women were more vulnerable owing to their weaker nervous systems. Allbutt \& Rollesten, in their weighty multivolume medical textbook, wrote in the chapter on neurasthenia "Young women are much more prone than young men to break down in this way". They also voiced the common concern that the increasing tendency to educate women could be leading to problems: "Many women never get over a long and ambitious course of study ... Many a brilliant student or vigorous athlete has been thus wrecked, perhaps for 
life - especially among women" (Allbutt \& Rolleston, 1905-1911).

\section{Disappearance of neurasthenia}

Like hysteria, there has been an apparent diminution of the prevalence of neurasthenia to the point where it actually disappeared (Wessely, 1990; Micale, 1995). Some writers have assumed the reality of this diminution and have attempted to explain it in various ways. Feminists have pointed to the emancipation of women and liberation of sexual attitudes as important in decreasing women's need to express themselves somatically (Showalter, 1985; Smith-Rosenberg, 1985). Within the medical profession the development of ideas about the unconscious and the increase in psychological treatments are postulated as a reason for the disappearance of disorders that were a physical expression of distress (Swartz et al, 1986). Shorter (1992) explains the decreased prevalence of neurasthenia as being due to a paradigm shift in medicine in which neurasthenic symptoms came to be regarded as caused in the mind. Somatising patients therefore selected other symptoms from the symptom pool, seeking refuge in other diagnoses with a more organic flavour. However, it is possible that neurasthenia as a symptom complex never actually disappeared, but was simply relabelled as medical nosology evolved. This argument is made by Micale, who emphasises 'diagnostic drift' in the evolution of disease categories (Micale, 1995). The same point is made by Wessely, who provides evidence from primary sources that symptoms of neurasthenia were replaced by psychological symptoms (Wessely, 1996). He also suggests a continuity between neurasthenic states and the modern and equally fashionable diagnosis of chronic fatigue syndrome or myalgic encephalitis (ME) (Wessely, 1990).

\section{Abandonment of neurasthenia by neurology}

The development of theories about psychogenic mechanisms began to take its toll on the notion of neurasthenia as a functional physical illness. Shorter describes how other psychiatric diagnoses gradually stripped away parts of the neurasthenia syndrome. For example, in 1895 Freud removed anxiety neurosis from neurasthenia (Freud, 1895) and in 1903 Janet introduced the term psychoasthenia, whose core was obsessive-compulsive states (Shorter, 1992). Meanwhile, neurologists were moving in an organic direction, being increasingly preoccupied with the huge strides they were making in terms of functional localisation of the workings of the nervous system (Bynum, 1985). Unfortunately, neurasthenia remained stubbornly a 'functional' disorder for which they had been unable to find any structural pathology (Gowers, 1893). Bynum (1985) argues that by the First World War most leading neurologists in Britain had left the treatment of functional disorders to their psychiatric colleagues. Writing about the British experience Wessely declares that "Neurasthenia was never accepted by the Medical Establishment", "the giants of the profession (neurology), such as Gowers, Gordon Holmes, Ferrier, Buzzard and KinnierWilson based at the National Hospital for Nervous Diseases, declared themselves in various ways against an organic view of neurasthenia" (Wessely, 1996). He poses the interesting question of whether their 'academic disdain' translated into their clinical practice. This question can be answered directly by the data produced by the current study, and it will also be possible to examine the extent to which neurologists continued to treat neurasthenia after the turn of the century.

\section{METHOD}

\section{Setting}

The National Hospital for the Relief and Cure of the Paralysed and Epileptic, as it was originally called, was opened with 10 beds in a house in Queen Square, London in 1860. It was the first ever hospital that specialised solely in the treatment of disorders of the nervous system (Rawlings, 1913). It was a charitable hospital and, as its rules make it clear, it aimed to provide treatment for the poor: "Due inquiry will also be made as to the social position of the applicant, as no person can become a patient who is capable of paying for medical treatment" (Queen Square Hospital Annual Report, 1867). The hospital grew rapidly over the next four decades, having 100 beds by 1871 and 200 by the turn of the century. It became a centre of excellence, in teaching, treatment and research, attracting patients from all over the country and even from abroad (Rawlings, 1913). Its early physicians count among the great names of the development of British neurology. For this reason its records provide a direct conduit to the medical practice and thinking of a crucial period in the development of the neurological speciality. It was well established throughout the period in which neurasthenia as a diagnosis appeared.

\section{Primary sources available at Queen Square}

Three main primary sources are available at the hospital. First, there are the annual reports of the hospital, which cover the period from the creation of the hospital in 1860 to 1947 . For most years the annual reports contain a medical registrar's report, which presents statistical returns of the number of discharges broken down by diagnosis, gender and outcome. Second, the hospital archive keeps the clinical casebooks (1853-1947), each bound according to the year, the consulting physician and the gender of the patient. Third, the library holds a historical collection consisting of 3000 books and monographs, all catalogued and this catalogue is available on the hospital website. Although some are older the majority of these are 19th century. There are also discrete collections of publications by staff who worked at Queen Square during their careers, which were kept up until 1980. The historical collection has grown with the hospital, and reflects the kind of textbooks, pamphlets and monographs that would have been available to physicians working at the hospital in the 19th century.

\section{Use of primary sources}

The bulk of this study focused on detailed reading of the annual reports. All changes in the classificatory system of 'functional disorders' were recorded. A paradox database was used to record for each year the number of neurasthenia diagnoses and the numbers of all other functional diagnoses, by gender. In order to have a denominator total discharges were recorded for each year. To enable comparison with a usually unambiguous organic diagnosis I recorded the number of brain tumour diagnoses for each year by gender.

The clinical case records were not studied in detail but were examined primarily to answer the following specific questions.

(a) What kinds of cases attracted the diagnosis of neurasthenia?

(b) What were the occupations of the patients diagnosed with neurasthenia? 
(c) Was the diagnosis widely used by all physicians, or was it an idiosyncratic diagnosis of one or two physicians?

Finally, I looked at the writings of the main consulting physicians over this period: Dr J. Hughlings Jackson (1835-1911), Sir J. Russell Reynolds (1828-1896), Dr Thomas Buzzard (1831-1919), Dr H. C. Bastian (1837-1915), Sir William Gowers (1845-1915), Sir David Ferrier (18431928), Dr C. E. Beevor (1854-1908) and Dr Kinnier Wilson (1878-1937). This will not be reported on in detail here, but my main aim was to ascertain their level of academic interest in the diagnosis. I also looked at which texts on neurasthenia were available in the library just before and after the turn of the 20th century, to ascertain what the physicians and their students might have been reading about the disorder.

\section{RESULTS}

\section{Qualitative data on neurasthenia from the annual reports}

Placing neurasthenia in the context of its time

Neurasthenia was one among many disorders regarded as 'functional'. This term did not carry any of its modern undertones of 'psychological' or even 'factitious', but meant a condition in which no anatomical abnormality of the nervous system had been detected, that is, the disturbance was one of function. Another interesting contrast with today is that the 'heartsink' reaction now engendered by functional patients was absent. There are frequent comments throughout the reports on the good results obtained in functional disorders compared with organic disorders. Such diseases were clearly regarded as legitimate cases for neurology, and indeed it is frequently stressed that they benefit particularly from hospital treatment. "In no class of disease treated in the Hospital have the results been better than in that of Hysteria and Nervous Exhaustion. It is often difficult to treat such patients in their home, where their own friends are frequently their worst enemies" (1882 medical registrar's report in the Queen Square Hospital Annual Report, 1883). Of course, it has to be borne in mind that the annual reports were written to satisfy subscribers that their money was being well spent.

We are reminded of the complete separation of these functional disorders from insanity by the rules of the hospital, which specifically exclude “... persons of unsound mind". The reports also include references to aetiology, which are interesting in that they were written by physicians for the general public. There is a resonance with modern ideas about the aetiology of chronic fatigue, for example, in the report of 1894 :

"The recent epidemics of influenza have not only been directly responsible for many of the cases under the head 'neurasthenia' and 'functional paralysis', but also indirectly by weakening the nervous system, have made patients liable to many other forms of nervous disease, which, but for the antecedent influenza they would probably have escaped. The over pressure of the present day, the race among the lower middle classes and the poor - not to get rich, but to escape poverty, and the financial disasters and frauds of the last few years, have all conduced to increase the number of cases of nervous diseases applying for treatment." (Queen Square Hospital Annual Report, 1894)

\section{Quantitative data on neurasthenia from the annual reports}

The prevalence of the diagnosis of neurasthenia as a proportion of total discharges for the period under study is shown in Fig. 1. The diagnosis makes its first appearance in 1886, after which it follows a steep and almost linear increase, peaking in 1906 at $11 \%$ of all discharges. There is a sharp fall from this peak in 1908, the diagnosis averaging $7.4 \%$ of all discharges until another sharp peak of $10 \%$ in 1920 , and a further peak of $11 \%$ in 1928 . This is followed by an abrupt decline down to only $3 \%$ in 1930 , and $1 \%$ in 1935 after which it vanishes. The prevalence of the diagnosis was on a par with the major organic categories treated, for example brain tumour, the prevalence of which remained at between 5 and $10 \%$ of total discharges over the period of this study. Figure 2 displays the gender breakdown of the diagnosis of neurasthenia.

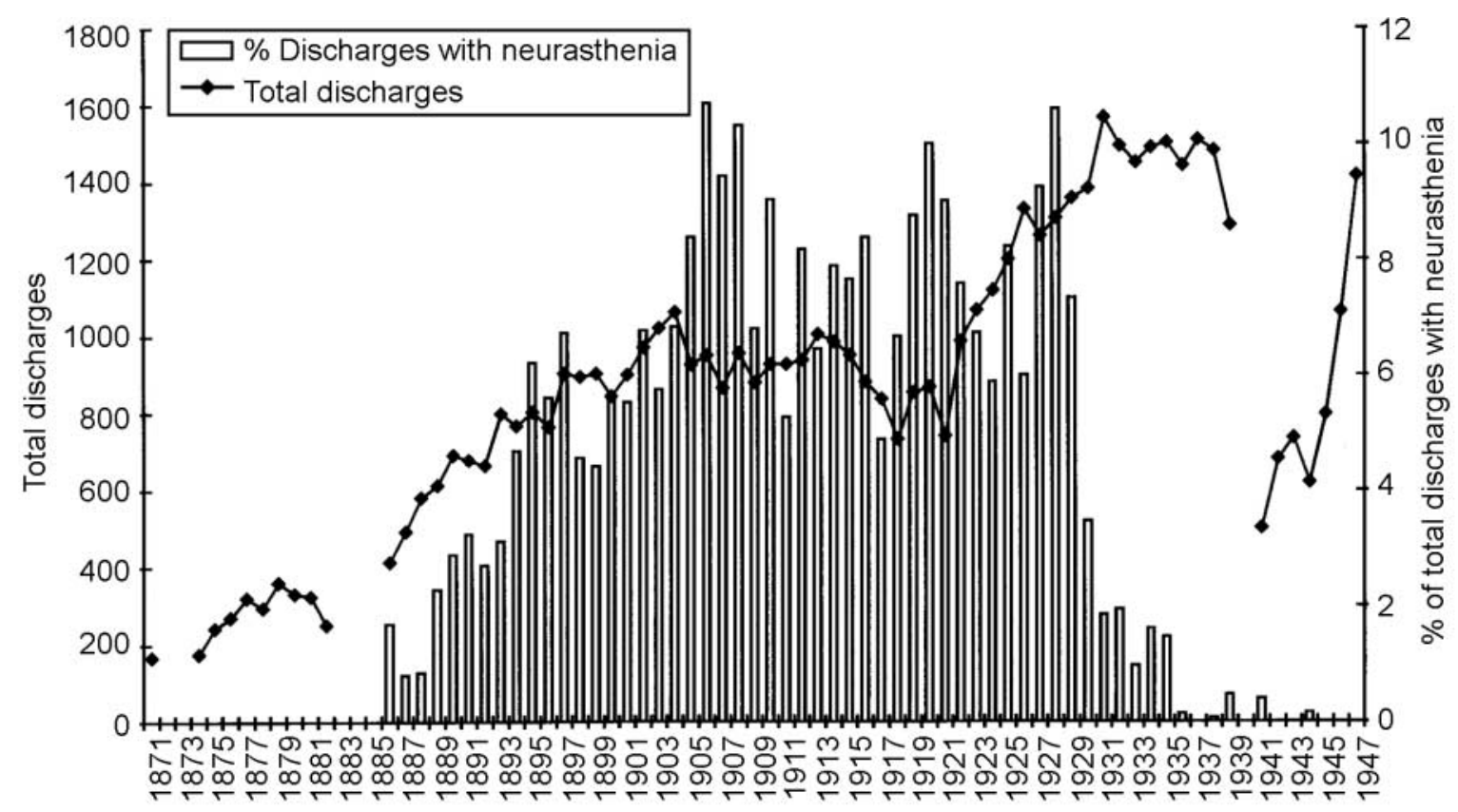

Year

Fig. I Percentage of Queen Square discharges with neurasthenia for 1870-1948. 


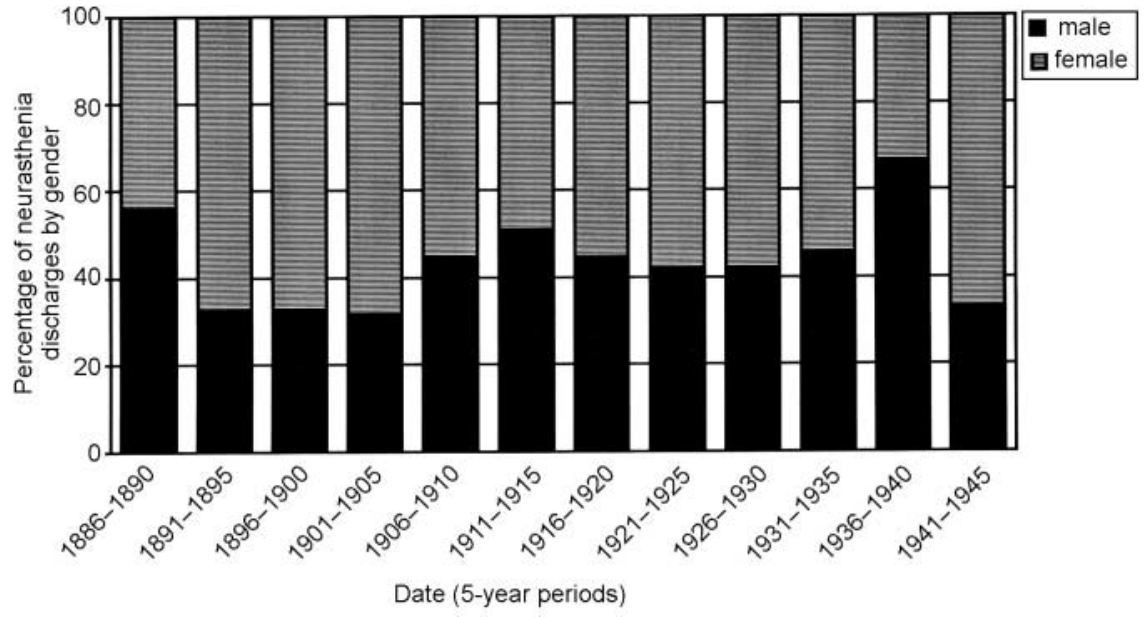

Fig. 2 Queen Square discharges with neurasthenia for 1870-1940: gender breakdown.

Changes in the way in which functional disorders were classified over the period under study were all identified and are shown in Table 1. From its first appearance in 1886 neurasthenia appears as a separate category in every statistical return until it suddenly vanishes, and becomes a subcategory of the 'psychoneuroses' in 1932. After 1941 neurasthenia disappears altogether and is not even a sub-category of the psychoneuroses (apart from one case in 1944). Figure 3 demonstrates the prevalence of all the psychoneurosis subcategories in 1932 added together, including the now small neurasthenia category,

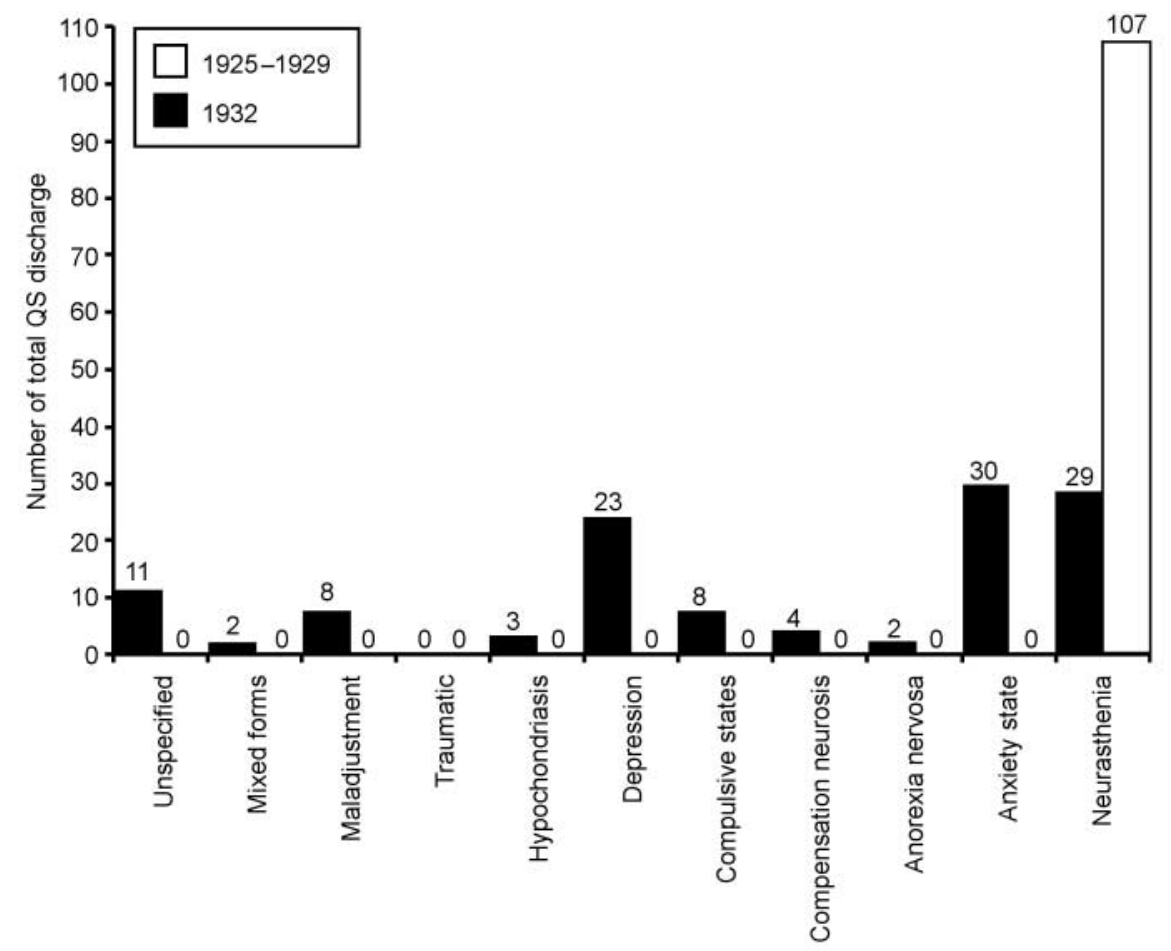

Fig. 3 Queen Square (QS) discharges: neurasthenia (1925-1929), psychoneuroses including sub-category of neurasthenia (1932). cases with diagnoses of neurosis from the 1930s.

The patients with neurasthenia, like other Queen Square patients, were from the working classes, having occupations such as 'parlour maid', 'horn worker' and 'crinoline and stay-maker'. The diagnosis of neurasthenia was made regularly by all the consulting physicians.

\section{Examination of the library historical collection}

Reading of publications by consulting physicians at Queen Square reveals that none had a specific academic interest in neurasthenia. Both Gowers (1893) and Beevor (1898) wrote neurology textbooks within which they included sections on the diagnosis. Gowers devoted one page to it in his first edition of 1888 , and this had increased to six pages in the second edition of 1893 . He remains sceptical about the diagnosis, suggesting that:

"there is no more justification for regarding
neurasthenia as a definite malady. . . than there
is for adopting a similar course with regard to
debility" (Gowers, 1893: 1045).

Despite this he admits that "there are many cases for which it is a convenient designation" and goes on to give a detailed description of the syndrome. Kinnier-Wilson's Modern Problems in Neurology (Wilson, 1928) does not index neurasthenia, although the author was still making the diagnosis. There were no scientific papers published at Queen Square on the aetiology or treatment of neurasthenia. Instead, they seem to have relied on other authorities (mostly American). For example, the library contains specific texts on neurasthenia from the 19th century by Thomas Stretch Dowse (1892), Silas Weir Mitchell (1881, 1884) and Thomas Saville (1899).

\section{DISCUSSION}

\section{Methodological strengths and weaknesses}

A strength of the study is that it is based directly on empirical data from annual reports, and these are remarkably complete. Detailed discharge statistics written by the medical registrar are available for every year from 1871 to 1947 , with data missing for only 6 years $(1872,1873,1883-1885$, $1940)$. The case records are also very complete, legible and have been subject indexed from their beginning to 1931. A potential 
Table I Changes in classification of 'functional' disorders in annual statistics of discharges reported in Annual Reports at Queen Square I87I-1932

\begin{tabular}{|c|c|c|}
\hline Year & Classificatory changes & Medical registrar \\
\hline 1871 & No functional or hysterical categories, no neurasthenia & No name \\
\hline 1874 & Hysteria category appears & No name \\
\hline 1882 & 'Hysteria and nervous exhaustion' grouped together & Dr C. F. Coxwell \\
\hline \multirow[t]{2}{*}{1886} & First appearance of neurasthenia & Dr Thomas Wilson \\
\hline & No hysteria category, just hystero-epilepsy & \\
\hline \multirow[t]{2}{*}{1888} & Functional category appears - 'functional monoplegia' & Dr Risien Russell \\
\hline & Hystero-epilepsy still there, separate from epilepsy. Separate hysterical category & \\
\hline 1889 & Hysteroid fits included with hysteria & No name \\
\hline 1890 & Functional category was 'functional hemiplegia' & Dr James Taylor \\
\hline 1891 & No category of hysteria, hysteroid fits only; functional category is 'functional paraplegias' & Dr James Taylor \\
\hline 1897 & Functional paralysis and functional spasm also appear under functional category & Dr A. J. Whiting \\
\hline 1902 & Hysteria category is back. Functional list lengthens to include: fits, paralysis, spasm & Dr G.W. Howland \\
\hline \multirow[t]{2}{*}{1904} & No hysteria category, but hysterical fits. Functional categories are paralysis and tremor & Dr T. Grainger- \\
\hline & & Stewart \\
\hline 1906 & No hysteria category; or hysteroid. More functional categories: fits, paralysis, spasm, tremor & No name \\
\hline 1908 & Hysteria is back, under functional: fits, palsies, tremor & Dr S. A. K. Wilson \\
\hline 1909 & Traumatic neurasthenia appears as a sub-category of neurasthenia, psychasthenia appears & Dr S. A. K. Wilson \\
\hline 1910 & Hysteria is back and hysteroid epilepsy, hysterical paralysis. No functional categories & Dr S. A. K. Wilson \\
\hline 1915 & 'Hysteria and neuroses' grouped together. Still no functional category. New category of 'mutism' appears & Dr P.W. Saunders \\
\hline \multirow[t]{2}{*}{1916} & $\begin{array}{l}\text { Malingering appears. Neuroses appear: ‘hysteria and neuroses' grouped together. Shell shock appears } \\
\text { (for just this one year) }\end{array}$ & Dr P.W. Saunders \\
\hline & Psychasthenia has gone. Functional category returns enlarged to include: aphonia, hemiplegia, monoplegia, paraplegia & \\
\hline \multirow[t]{2}{*}{1917} & Neurosis appears alone & \\
\hline & $\begin{array}{l}\text { Huge number functional categories: amblyopia, aphonia, deaf mutism and paraplegia, fits, hemiplegia, monoplegia, } \\
\text { paraplegia, paraplegia and mutism, tremor, tremor and stammering. Psychasthenia back }\end{array}$ & \\
\hline 1918 & No functional category, but all the above which were under functional are now sub-categories of hysteria. Neurosis gone & Dr L. Yealland \\
\hline \multirow[t]{3}{*}{1921} & Anxiety neurosis appears for first time and neurosis reappears & Miss M. A. Blandy \\
\hline & Hysteria there with sub-categories: palsy, fits, tremor & \\
\hline & Hypochondriasis appears & \\
\hline 1923 & Anorexia nervosa appears for first time & Miss M. A. Blandy \\
\hline 1930 & Neurosis appears with sub-categories: anxiety, compulsion, obsessional, traumatic & Dr D. Denny-Brown \\
\hline \multirow[t]{2}{*}{1931} & Psychoneurosis appears for first time & Dr D. Denny-Brown \\
\hline & Neurosis with above sub-categories & \\
\hline 1932 & $\begin{array}{l}\text { Neurasthenia disappears as a category on its own. Large category of psychoneuroses appear with } \\
\text { sub-categories: anxiety state, anorexia nervosa, compensation neurosis, compulsive state, } \\
\text { depression, hysteria, hypochondriasis, maladjustment, mixed forms, neurasthenia, unspecified }\end{array}$ & Dr D. Denny-Brown \\
\hline
\end{tabular}

weakness could be the fact that I gathered all data, raising the possibility of bias. However, because the data are quantitative and the collection process involved direct recording of numbers of discharges with a particular diagnosis on a database, there is no room for distortion of the data as the process involved no subjective interpretation. The study obviously only informs us about one particular specialised hospital and is not generalisable to other hospitals. It also tells us nothing about what was going on in private practice. However, the hospital studied was a pre-eminent centre in the treatment of nervous diseases, and its physicians were representative of the leading academic neurologists of the time. The study therefore informs us about the diagnostic practice of this influential group.

\section{Social class and neurasthenia}

The data presented in Fig. 1 contradict the myth outlined earlier that neurasthenia was a disease of the wealthy classes, thus failing to support the first hypothesis. Queen Square, a hospital providing charity treatment for the poor, treated large numbers of cases of neurasthenia throughout the heyday of the diagnosis. The case-records information on occupations of patients confirm that they were from the working classes.

It is interesting that there is a lag of $\mathbf{1 7}$ years from Beard's first introduction of the term in 1869 to the first appearance of the diagnosis in Queen Square discharges. This may reflect the length of time it took the diagnosis to cross the Atlantic, as most of the references to it being the fashionable disease in Europe are from around the early 1890s (Wessely, 1996). Thus, it seems that it appeared and became prevalent in the working classes at about the same time as it was appearing in large numbers of their 
upper-class counterparts. This contradicts Wessely's (1996) suggestion that there was a gradual movement of the disease down the class structure. The textbooks in Queen Square library provide further evidence that physicians at the time observed that it was not only an upper-class disease. Thomas Saville (a London neurologist working at Paddington Infirmary) wrote in his Clinical Lectures on Neurasthenia (1899) about the frequency of the diagnosis among the poor and inmates of the Paddington workhouse (Saville, 1899). He made some epidemiological observations on the disease, comparing rates in these settings with those he encountered in his private practice, and concluded that there was no social-class trend.

\section{Gender and neurasthenia}

The data on gender in Fig. 2 dispel the second myth, that neurasthenia was largely a female illness, and so do not support the second hypothesis. When the diagnosis first appears the gender split is about 50/50, and even though the proportion of males falls to a low in 1891-1905, it is never lower than about one-third. The male prevalence then increases until there is a slight male excess in 1911-1915. (This excess actually continues into the next 5-year time block until 1918 , but then a female excess returns so overall the period 1916-1920 shows a slight female excess.) The increase in male neurasthenia during the war years is almost certainly explained by its occurrence in servicemen returning from the Western front. Between 1914 and 1918 one-third of the beds available at the hospital were used for military cases (Queen Square Hospital Annual Reports, 1914-18), and the medical registrars' reports comment on the high frequency of functional disorders among this group. The number of males affected just after the war is probably an underrepresentation, as in 1918 the hospital opened a special house for the treatment of servicemen with neurasthenia, and many more men would have been admitted there. However, the war does not entirely explain the increased male prevalence of neurasthenia, as it is already more common in men by 1910 ( $56 \%$ male, $44 \%$ female).

\section{Disappearance of neurasthenia}

Figure 1 gives a vivid display of the rise and fall of neurasthenia. Particularly striking are its abrupt appearance in 1886 and equally sudden disappearance after 1930 . This type of pattern might fit with a disease of infectious origin during an epidemic, a possibility which cannot be entirely discounted. A major epidemic of encephalitis lethargica swept across Europe in 1915, and some authorities describe earlier epidemics (Brain, 1955). It is possible that neurasthenia represented a form fruste of the disease, or a post-viral fatigue state following influenza epidemics. The quote above from the annual reports indicates that doctors at the time linked neurasthenia to influenza. It would be possible to trace the major influenza epidemics in the 19th century to see if these related to the fluctuations in neurasthenia, but this is beyond the scope of the current paper.

An alternative explanation for the pattern seen is that it is due to changes in medical nosology. In Table 1 we see that although psychological categories came and went, they were not enduring and were never large, and so could not account for many cases. The abrupt fall in prevalence of neurasthenia in 1930 coincides with the reappearance of neurosis split into four sub-categories, which changes in 1932 into a bigger and enduring category of psychoneurosis split into 11 sub-categories, one of which is neurasthenia. Figure 3 illustrates that if all the psychoneurosis sub-categories in 1932 are added together they account for a similar proportion of total discharges (about 8\%) which neurasthenia had accounted for previously. Thus, although neurasthenia apparently disappeared abruptly in 1932 apparently supporting Hypothesis 3, closer examination of the data has provided strong evidence that it was reclassified into the psychoneuroses, which continued to constitute just under one-tenth of all discharges. The case histories demonstrate that those with a diagnosis of neurosis in the 1930s had a symptom cluster common to earlier cases diagnosed as neurasthenia (see Appendix).

\section{Did neurologists abandon neurasthenia?}

The data presented here suggests that neurologists did not stop seeing and admitting neurasthenia patients after 1900 - thus Hypothesis 4 is not supported. Contrary to Bynum's view, they had not handed neurasthenia over to their psychiatric colleagues by the turn of the century, as the diagnosis was made in at least $8 \%$ of the patients they admitted for three decades after that. Even when it apparently disappears in the 1930s they were probably continuing to see similar cases, but they were now making psychological diagnoses. The reasons for the persistence of such cases in neurological practice can only be speculated upon here. The asylums were only just beginning to take an interest in the 'minor' or neurotic mental disorders in the 1920s; for example the Maudsley Outpatient Department did not open until 1923 (Maudsley Hospital Annual Report, 1924). There may well have been a shortage of suitably trained psychiatrists, and the stigma of psychiatry as a speciality that dealt with the insane may have created a reluctance in people to seek help in that quarter. Although neurologists had clearly started making mental diagnoses at Queen Square in the 1930s, it is an interesting question as to whether they were using specific psychological treatments. This could be ascertained by a more detailed study of the case records.

Examination of the case records confirmed that the diagnosis of neurasthenia was frequently made by all the consulting physicians. However, examination of the scientific writings of those same physicians demonstrates their lack of academic or research interest in the diagnosis. This confirms Wessely's suspicion that the academic disinterest of Queen Square physicians was not mirrored in their clinical practice. It seems that neurasthenia was not a very satisfying diagnosis to them, but it was a useful and pragmatic description of a large number of the patients who sought their advice.

\section{ACKNOWLEDGEMENTS}

I thank the following: Dr Kelly Loughlin and Professor Virginia Berridge of the History of Medicine Unit at the London School of Hygiene and Tropical Medicine for their helpful advice. Dr Nicholas Moran for invaluable help with the database used. Mr Steve Wilson (archivist and librarian), Ms Louise Shepherd (librarian) and Professor Maria Ron (Professor of Neuropsychiatry) at the National Hospital for Neurology and Neurosurgery for their help in accessing historical materials.

\section{APPENDIX}

\section{Case histories}

\section{Examples of neurasthenia cases}

1867: 53-year-old female, no occupation.

Dr Ramskill: diagnosis neurasthenia

"Talk very nervous and excitable. Complains of
mistiness of vision and palpitations and of general
weakness, chiefly of both arms and right leg,
right foot is very numb. . . Does not drag right
leg when walking. Complains of great pain in arm
if she attempts any work. Ceased to menstruate 
3 years ago. Has not been able to do any work for a year."

\section{1: 34-year-old female, no occupation.}

\section{Sir D. Ferrier: diagnosis neurasthenia}

"III for past 22 months. Sudden onset January 1890 started out of bed with a vague feeling of fear, no pain, doctor came, temperature was 105 . . told she had influenza. Weak all over, in bed 3 days or more, and since then till time of pregnancy of last child October 1890 has been very delicate but able to attend her household duties, and go for short walks. During her pregnancy felt very weak. Often unable to walk to bed but no other symptoms except giddiness and a trembling in the legs. Has had no return of starting fits but feels very uneasy generally, is sleepless, irritated by small noises, but not restless. Feet always feel cold, suffers from palpitations. Bowels constipated."

1900: 25-year-old female, husband a labourer. Sir Gowers: diagnosis neurasthenia

"Complaint: headache; backache; palpitations; indigestion; shortness of breath; pricking and jumping pains all over. Duration 3 years."

\section{5: 40-year-old male, office manager.}

Dr Howells: diagnosis neurasthenia

"Complaint: Pressure in the head. Stabbing frontal and occipital headaches. Weak tired feeling. Tingling in arms and legs. Inability to concentrate. Restlessness, irritability and indecision. Insomnia. 6-7 years duration."

\section{Cases of anxiety neurosis}

1930: 34-year-old male clerk. Dr Holmes: diagnosis neurosis

"After the war age 30 went back to work as a clerk. Afraid of meeting people. Urgency which exacerbated it. Had to give up work. Ordered to bed for some time by his doctor. It was as if he had lost all his power and he could not walk more than fifty yards. When he got up he felt better but he was ordered to have 2 months rest. After this he went back to his work - he felt much better and kept at work about 2 years before he got the next bad attack of nervous exhaustion after which he had to give up work for about 3 weeks. Since end December gradually worse. He had gradually lost his power more and more, but kept at work. When he came home in the evening he felt entirely exhausted and could not do anything but go to bed. He felt immensely tired and used all his spare time and weekends to lie down for rest. His sleep is all right but when he awakens in the morning he feels as if he has not had enough rest."

1935: 50-year-old female, husband warehouseman. Dr Holmes: diagnosis anxiety neurosis

"III for 5 years. Complaint: Pain in left occipital region. Constant pain last 2 years in left occipital region and also at the vertex. Now cramp like in

\section{CLINICAL IMPLICATIONS}

- A core cluster of non-specific unexplained symptoms can be identified in historical case records, and has remained a significant proportion of the cases presenting to doctors in the past two centuries.

- The diagnostic categories used by doctors to make sense of these unexplained symptoms have fluctuated over time, with a shift in the 20th century to psychological diagnoses.

- Patients with unexplained physical symptoms have always been common, they suffer considerably, and over two centuries have passed to and fro between physicians and psychiatrists. We have few more clearly effective management strategies for this group than they had in the 19th century.

\section{LIMITATIONS}

- The study is based on historical records in only one hospital specialising in the care of neurological illness. It may therefore not be representative of the wider situation.

- It was beyond the scope of the current study to look in detail at the case books. This would provide a clearer picture of why the diagnosis of neurasthenia was used by physicians who were at times critical of it or at least had little academic interest in it, and what it communicated between physicians.

- During the 19th century most medical care for the wealthier classes took place in private practice, and the current hospital-based study can give us no information about this large area of medical practice.

RUTH E. TAYLOR, MRCPsych, Department of Psychiatry, St Bartholomew's and the Royal London School of Medicine and Dentistry, Basic Medical Sciences Building, Queen Mary and Westfield College, Mile End Road, London El 4NS, UK

(First received 26 July 2000, final revision 20 November 2000, accepted 2 December 2000)

character and has affected the left side of the neck, so that she is unable to move her head without increasing the pain. Headaches are present 2-3 times per week. They consist of a generalised tight feeling all over the scalp and she feels as if machinery is going inside. She has become weak recently and is only able to do her housework with difficulty.

Her legs ache after exercises and she tires easily. She is very emotional and becomes depressed over the slightest thing.

She cannot sleep at night. She says she feels as if she cannot manage to keep going."

\section{4: 59-year-old female, lace cutter}

Dr Collier: diagnosis anxiety neurosis

"Well until 4 years ago when she began to suffer from pain in the spine from the lower part of the neck right to the bottom . . . . Has been in the Nottingham General Hospital and had "all kinds of treatment" with absolutely no effect". Some 3 years ago she began to experience a feeling of coldness in her head, and this likewise has persisted . . . it is all over her head on both sides and is a combined sensation of numbness and coldness. Occasionally it pervades her face for a day or two .... At times too her tongue and throat feel cold and at other times they feel burning hot so much so that swallowing is painful. These symptoms have likewise not been benefited at all by treatment .... . She feels weak all over and occasionally the use seems to go out of her left foot. Her legs feel numb and heavy and her hands and feet tingle and occasionally "go all scarlet". . . . Two years ago she had what she described as a "stroke". She went black and seemed to lose all power in her arms and legs for a few moments. She was completely restored by a little brandy."

\section{REFERENCES}

Allbutt, T. C. \& Rolleston, H. D. (eds) (1905-19II) A System of Medicine. Vol III. Diseases of the Brain and Mental Diseases, pp. 134-163. London: McMillan and Co. 
Beard, G. (1869) Neurasthenia, or nervous exhaustion. Boston Medical and Surgical Journal, 3, 217-221.

- (1972) American Nervousness: Its Causes and Consequences (reprint edition). New York: Arno Press.

Beevor, C. E. (1898) Diseases of the Nervous System: A Handbook for Students and Practitioners. London: H. K. Lewis.

Blocq, P. (1894) Neurasthenia. Brain, 14, 306-314

Brain, R. (1955) Virus infections of the nervous system. In Diseases of the Nervous System (5th edn) (ed. R. Brain) pp. 45I-460. London: Oxford University Press.

Bynum, W. F. (1985) The nervous patient in eighteenth and nineteenth-century Britain: the psychiatric origins of British neurology. In The Anatomy of Madness. Essays in the History of Psychiatry (eds W. F. Bynum, R. Porter \& M. Shepherd), pp. 89-102. London: Tavistock Publications.

Chricton Miller, H. (1920) Functional Nerve Disease: an Epitome of War Experience for the Practitioner. London: Henry, Frowde, Hodder \& Stoughton.

Dowse, T. S. (1892) On Brain and Nerve Exhaustion (Neurasthenia), and on the Exhaustions of Influenza. London: BaillièreTindall and Cox.

Freud, S. (1895) On the Grounds for Detaching a Particular Syndrome from Neurasthenia under the Description 'Anxiety Neurosis'. Reprinted (1953-1974) in the Standard Edition of the Complete Works of Sigmund Freud (trans. and ed. J. Strachey), vol. 3, pp. 90-115. London: Hogarth Press.
Gosling, F. G. (1987) Before Freud: Neurasthenia and the American Medical Community, 1870-1910. Urbana, IL: University of Illinois Press.

Gowers, W. R. (1893) A Manual of Diseases of the Nervous System. Volume II. Diseases of the Brain and Cranial Nerves, General and Functional Diseases of the Nervous System (2nd edn). Darien, CN: Hafner Publishing.

Jewell, J. (188I) Influence of our present civilization in the production of nervous and mental disease. Journal of Nervous and Mental Disease, 8, I-24.

Maudsley Hospital Annual Report (1924) Maudsley Annual Report. Archives of the Bethlem Royal and Maudsley Hospitals, Bethlem Royal Hospital, London.

Micale, M. (1995) Approaching Hysteria. Disease and Its Interpretation. Princeton, NJ: Princeton University Press.

Mitchell, S.W. (1881) Lectures on Diseases of the Nervous System Especially in Women. Philadelphia, PA: Henry C. Lea \& Son.

- (1884) Fat and Blood: An Essay on the Treatment of Certain Forms of Neurasthenia and Hysteria (2nd edn). Philadelphia, PA: J. B. Lippincott.

Pritchard, W. (1905) The American Disease: an interpretation. Canadian Journal of Medicine and Surgery 18, $10-22$.

Queen Square Hospital Annual Reports (1862-1940) Archives of the National Hospital for Neurology and Neurosurgery, Queen Square, London.
Rawlings, B. B. (1913) A Hospital in the Making. London: Sir Isaac Pitman and Sons.

Saville, T. D. (1899) Clinical Lectures on Neurasthenia. London: Henry J. Glaisher.

Shorter, E. (1992) From Paralysis to Fatigue: A History of Psychosomatic Illness in the Modern Era. New York: Free Press.

- (1994) From the Mind into the Body: The Cultural Origins of Psychosomatic Symptoms. New York: Free Press.

Showalter, E. (1985) The Female Malady. Women, Madness and English Culture, 1830-1980. London: Virago.

Smith-Rosenberg, C. (1985) Disorderly Conduct: Visions of Gender in Victorian America. New York: Knopf.

Swartz, M., Blazer, D., George, L., et al (1986)

Somatization disorder in a community population. American Journal of Psychiatry, 143, 1403-1408.

Wessely, S. (1990) Old wine in new bottles: neurasthenia and 'ME'. Psychological Medicine, 20, 35-53.

- (1996) Neurasthenia and fatigue syndromes, part 3. In A History of Clinical Psychiatry (eds R. Porter \& G. E. Berrios), pp. 509-532. London: Athlone.

Wilson, S. A. K. (1928) Modern Problems in Neurology London: Edward Arnold. 